\title{
LA EXTENSIÓN DE JURISPRUDENCIA COMO MECANISMO PARA EL RECONOCIMIENTO DEL VALOR JURÍDICO DEL PRECEDENTE ADMINISTRATIVO EN COLOMBIA
}

The Extension of jurisprudence as a mechanism to recognize the legal value of the administrative precedent in Colombia

\author{
Yudy Carolina Leal Galán ${ }^{1}$
}

Fecha de recepción: 21 de abril de 2017

Fecha de aceptación: 04 de mayo de 2017

Sumario: 1. Introducción; 2. Mecanismo de extensión de jurisprudencia en el ordenamiento jurídico colombiano: aspectos generales y caracterización;

2.1 Origen del mecanismo; 2.2 Procedimiento de la extensión de jurisprudencia;

3. Ia jurisprudencia como fuente formal (análisis crítico); 3.1. Ventajas del sistema colombiano; 4. Conclusiones; 5. Referencias Bibliográficas.

${ }^{1}$ Magistrada auxiliar del Consejo de Estado. 


\section{CÓMO SE CITA ESTE ARTÍCULO (Normas APA-6)}

Leal Galán, Yudy Carolina (2017). La extensión de jurisprudencia como mecanismo para el reconocimiento del valor jurídico del precedente administrativo en Colombia. Revista Jurídica Mario Alario D’Filippo, IX (18), pág 76-92.

\section{RESUMEN}

El presente trabajo tiene por finalidad demostrar cómo a través del mecanismo de Extensión de Jurisprudencia, previsto en la Ley 1437 de 2011, la discusión acerca del carácter vinculante del Precedente Administrativo en Colombia puede resolverse, en el sentido de otorgarle a éste valor jurídico, a partir del reconocimiento de la Extensión, como una nueva forma de solución alternativa de conflictos entre la Administración Pública y el ciudadano. Partiendo de concebir la Extensión, como un derecho de petición especial que se debe responder por parte de Autoridad Pública atendiendo las directrices fijadas en las providencias judiciales emitidas por el Consejo de Estado y la Corte Constitucional, que hayan resuelto de manera uniforme un asunto semejante desde el punto de vista fáctico y jurídico.

\section{PALABRAS CLAVE}

Precedente Administrativo, Extensión de Jurisprudencia, Derecho de Petición, MASC.

\section{ABSTRACT}

The purpose of this paper is to demonstrate how, through the Case Law Extension mechanism, provided for in Law 1437 of 2011, the discussion about the binding nature of the Administrative Precedent in Colombia can be resolved, in the sense of granting it legal value, based on the recognition of the Extension as a new form of alternative solution of conflicts between the Public Administration and the citizens. It bases on conceiving the Extension as a special petition right that must be answered by the Public Authority in accordance with the guidelines established by the judicial orders issued by the Council of State and the Constitutional Court having resolved some issue uniformly from the factual and legal standpoint.

\section{KEYWORDS}

Administrative Precedent, Extension of Jurisprudence, Right of Petition, MASC. 


\section{INTRODUCCIÓN}

El Nuevo Código de Procedimiento Administrativo y de lo Contencioso Administrativo (en adelante CPACA), introdujo en el ordenamiento jurídico colombiano, la Extensión de la Jurisprudencia, como un mecanismo mediante el cual, se puede lograr que aquellos asuntos iguales o similares desde el punto de vista fáctico y jurídico, sean resueltos de la misma manera, mediante la aplicación uniforme de los criterios y directrices consignados en las providencias judiciales emitidas por el Consejo de Estado y la Corte Constitucional.

En este sentido, con esta investigación se trata de demostrar cómo a través del mecanismo de Extensión de Jurisprudencia previsto en los artículos 102 y 269 del CPACA, el Precedente Administrativo en Colombia adquiere fuerza vinculante, convirtiéndose en una nueva forma de solución alternativa de conflictos entre la Administración Pública y el ciudadano.

Es de resaltar que, el mecanismo en mención es una especie de derecho de petición especial mediante el cual se pretende lograr que aquellos asuntos iguales o similares desde el punto de vista fáctico y jurídico, sean resueltos en sede administrativa de la misma manera, mediante la aplicación uniforme de los criterios y directrices consignados en las providencias judiciales emitidas por las altas Corporaciones mencionas; lo cual, sin duda, ha de redundar en la descongestión de los despachos judiciales y en la creación de un clima de confianza y seguridad jurídica, haciendo posible el desiderátum que las autoridades administrativas sean mucho más justas, coherentes y predecibles al resolver los asuntos de su competencia, honrando con ello los postulados constitucionales de justicia e igualdad y los principios que gobiernan el ejercicio de la función administrativa.

Con ese propósito resulta de gran interés y pertinencia abordar el estudio de las distintas posiciones que sobre el particular se han decantado en el concierto internacional, especialmente en países como España y Costa Rica en donde la discusión ha estado en el orden del día, para luego aterrizar en el sistema nacional, con la más absoluta convicción de que ese ejercicio de derecho comparado será sin duda de gran utilidad y provecho.

El esfuerzo académico a emprender, involucra necesariamente la realización de los esfuerzos encaminados a precisar cuáles son los fines, requisitos y alcances de este novedoso Mecanismo, sin dejar de analizar con mirada crítica y constructiva las falencias y limitaciones que desde mi punto de vista presenta.

Así por ejemplo, se observa in limine que la Comisión Redactora del CPACA no tuvo en cuenta el impacto presupuestal que puede derivarse de la decisión de hacer extensivos los efectos de alguna jurisprudencia a quienes se encuentren en determinada situación 
fáctica o jurídica. Como es bien sabido, el inciso $1^{\circ}$ del artículo 71 del Decreto Ley 111 de 1976, por medio del cual se codificaron las normas orgánicas de presupuesto, establece de manera perentoria que todos los actos administrativos que afecten apropiaciones presupuestales, necesariamente deben contar con certificados previos de disponibilidad que garanticen la existencia de las apropiaciones presupuestales suficientes para cubrir estos gastos, norma ésta cuya inobservancia compromete la responsabilidad personal y pecuniaria de los servidores públicos que ordenen gastos o efectúen el pago de obligaciones en exceso de los saldos disponibles, tal como lo establece el artículo 48 numeral 23 del Código Único Disciplinario.

En virtud de lo expuesto, resulta imperioso diseñar una propuesta que haga posible la solución de este asunto tan trascendente, de cuya definición depende en buena medida el éxito de la figura.

\section{MECANISMO DE EXTENSIÓN DE JURISPRUDENCIA EN EL ORDENAMIENTO JURÍDICO COLOMBIANO: ASPECTOS GENERALES Y CARACTERIZACIÓN}

Hasta 2011 la posibilidad de que el Precedente Administrativo tuviese algún tipo de peso o valor jurídico en nuestro país era nulo, salvo la excepción ya planteada de la DIAN. Sin embargo, la expedición de la Ley 1437 de 2011 o CPACA ha hecho que la construcción de esa figura comience a avizorarse de manera seria y desde la posición del Juez, quien paradójicamente ha negado su valor.

Para ello es necesario comenzar por indicar que la inclusión de un nuevo deber de la Administración en la enunciada codificación ha reafirmado la intención legislativa de vincular a la Administración a sus propias decisiones, pues le ordena que cuando se encuentre frente a una situación que haya resuelto de manera similar en el pasado, debe darle el mismo tratamiento anterior. Éste aspecto viene a ser fortalecido con la creación del Mecanismo de Extensión de Jurisprudencia, que no es más que una herramienta del ciudadano para exigir de la Administración el cumplimiento de ese preciso deber.

El Mecanismo de Extensión de Jurisprudencia y sus consecuencias en la creación de Precedentes Administrativos se enmarcan perfectamente en el llamado "derecho social", es decir, la legislación que interesa al ciudadano medio, o las materias de lo que constituye el sistema jurídico del país, de las que la mayoría de la población espera algo para sí. (Novoa, 2007, p. 28-29).

Cuando la realidad social nos informa que vivimos en una sociedad muy fluida en cuanto a sus proyectos sociales, necesidades o costumbres, lo lógico es introducir un sistema legal nuevo que tenga como notas distintivas ser simple, preciso y fácilmente modificable conforme lo exija la comunidad, todo lo cual implica sin duda una reformulación de los medios que se necesiten para alcanzar unas metas mínimas de comodidad. 
Para alcanzar esas metas, resulta pertinente traer a colación lo que propone Eduardo Novoa Monreal en su libro El derecho como Obstáculo al Cambio Social, en el que plantea una serie de requisitos para que las nuevas condiciones de la vida social no den al traste con el sistema jurídico que las gobierna, veamos:

1. Un sistema legal nuevo que exprese las necesidades del momento, 2. Integración de las normas en un cuerpo único, bien articulado y coherente, 3. Flexibilidad en sus preceptos, de modo que se puedan ir poniendo a tono con las exigencias que se vayan presentando y por último, 4. Estar compuesto por un número reducido de preceptos claros, ordenados y precisos. (2007, p. 66)

La Ley 1395 del 12 de julio de 2010 es una muestra de lo anterior, pues dispuso otorgar carácter vinculante a las providencias que los órganos de cierre de las Jurisdicciones Ordinaria y Contenciosa Administrativa emitan en ciertas materias, esto es, cuando compartan un discernimiento judicial unificado. La creación de esta norma se dio por la necesidad de que las autoridades administrativas acataran los pronunciamientos que los jueces de manera reiterada y pacífica habían emitido en ciertos asuntos, de modo que no obligasen al ciudadano a agotar un proceso judicial para que le reconocieran un derecho que bien pudo ser reconocido en sede administrativa, esto es, sin acudir a instancias judiciales ni pasar largos años en espera de una decisión definitiva. Para evidenciar ello basta leer el artículo 114 del CPACA.

Incluso, en el trámite del Proyecto de Ley que después se convertiría en el Código de Procedimiento Administrativo y de lo Contencioso Administrativo, cuando hacía tránsito en la Cámara de Representantes, se quiso incluir un segundo inciso que refleja con claridad el interés del Legislador por garantizar la aplicación directa de los Precedentes jurisprudenciales reiterados del Consejo de Estado. Ese inciso segundo señalaba algo semejante a la norma transcrita, veamos:

En todo caso, las entidades públicas de cualquier orden, encargadas de reconocer y pagar pensiones de jubilación, prestaciones sociales y salariales de sus trabajadores o afiliados, o comprometidas en daños causados con armas de fuego, vehículos oficiales, daños a reclusos, conscriptos, o en conflictos tributarios o aduaneros, para la solución de peticiones o expedición de actos administrativos, tendrán en cuenta los Precedentes jurisprudenciales que en materia ordinaria o contenciosa-administrativa, por los mismos hechos y pretensiones, se hubieren adoptado en sentencias de unificación jurisprudencial, de acuerdo con lo dispuesto en este Código. (Ponencia para primer debate al Proyecto de Ley Cámara, 198 de 2009 Senado, por el cual se expide el Código de Procedimiento Administrativo y de lo Contencioso Administrativo, Art. 10, párr. 2).

Sin duda, la aprobación de la enunciada Ley responde a las necesidades de que a la comunidad le sean resueltas sus peticiones atendiendo las normas que orientan la 
situación que se pone a consideración de la Administración y la interpretación que sobre ciertas materias haya hecho la Jurisdicción correspondiente.

Tal propósito se vio posteriormente reflejado en una norma más concreta y mejor desarrollada, en la medida en que articuló una concepción filosófica del Precedente Administrativo con una práctica traducida en la creación de un instrumento al servicio del ciudadano que pudiera hacer efectiva la garantía constitucional a gozar de igual trato ante situaciones similares. Se trata de manifestaciones fieles del derecho social, ya que, como veremos, cumple con los presupuestos mencionados para hacer parte de esta nueva rama del derecho: 1 . Expresa una necesidad actual de que las situaciones jurídicas de los particulares se resuelvan en sede administrativa y no en la judicial, 2 . Se encuentra integrado en el CPACA, código que regula la actuación de la Administración Pública y ante la Jurisdicción de lo Contencioso Administrativa, que es la encargada de controlarla, 3. La necesidad de consultar la jurisprudencia pone el Mecanismo a tono con la necesidad actual de la comunidad, y 4 . La regulación de este Mecanismo se encuentra en buena medida ordenada, y clara en su procedimiento².

\section{1 ORIGEN DEL MECANISMO}

Tal figura se concibió desde el año 2007, cuando la Jurisdicción de lo Contencioso Administrativo vio la necesidad de "repensar" el papel que venía desempeñando, producto de lo cual se aprobó la Ley 1437 de 2011 o CPACA, norma ésta que fue el resultado de un interesante proceso de concertación entre las ramas del poder público y de reconocidos doctrinantes nacionales.

Pues bien, tras más de cuatro años de largas discusiones la Comisión de Reforma al Código Contencioso Administrativo o Decreto Ley 01 de 1984 (en adelante CCA) replanteó el papel que debía desplegar el Juez Administrativo y ayudó a detectar la fuente de la conocida congestión y mora de los jueces en nuestro país, esto es, el desplazamiento de las decisiones que debía adoptar la Administración Pública hacia los Despachos Judiciales. Así, el juez terminó por sustituir al órgano de ejecución del aparato estatal y éste (la Rama Ejecutiva) sometiendo al administrado a años de litigio en procesos que bien podían resolverse en sede administrativa.

Por esa razón, uno de los propósitos del nuevo código fue el de enfatizar en los deberes de esta rama del poder público, ideando como uno de los más importantes el que las autoridades administrativas apliquen en sus decisiones la Constitución, la Ley y los Reglamentos en igualdad de condiciones a quienes se encuentren en las mismas situaciones fácticas y jurídicas de asuntos ya resueltos por la jurisprudencia unificada del Consejo de Estado y de la Corte Constitucional ${ }^{3}$. El artículo 10 del CPACA es del siguiente tenor:

${ }^{2}$ Salvo en lo que respecta a la modificación de la que fue objeto en el Código General del Proceso.

${ }^{3}$ De acuerdo con la sentencia de la Corte constitucional que declaró la exequibilidad del artículo 10ำ, son vinculantes no sólo las 
Artículo 10. Deber de aplicación uniforme de las normas y la jurisprudencia. Al resolver los asuntos de su competencia, las autoridades aplicarán las disposiciones constitucionales, legales y reglamentarias de manera uniforme a situaciones que tengan los mismos supuestos fácticos y jurídicos. Con este propósito, al adoptar las decisiones de su competencia, deberán tener en cuenta las sentencias de unificación jurisprudencial del Consejo de Estado en las que se interpreten y apliquen dichas normas.

El primer inciso del citado precepto constituye la piedra angular del nacimiento normativo del Precedente Administrativo en Colombia en su concepción pura, es decir, sin que dependa de sentencias judiciales de unificación que lo formen, y si se quiere del Mecanismo de Extensión de Jurisprudencia.

Al analizar el contenido de la disposición, se pueden extraer las siguientes dos conclusiones: (i) la Administración debe aplicar de manera uniforme la Constitución, la Ley y los Reglamentos en casos similares, y (ii) La Administración debe extender los efectos de una sentencia de unificación del Consejo de Estado o de la Corte Constitucional que haya resuelto una situación semejante a la planteada por un particular.

A partir de esta norma, que no busca más que garantizar el derecho a la igualdad de los administrados, es que Juristas como Danilo Rojas Betancourt ${ }^{4}$ han afirmado que el primer inciso se refiere a la obligación de la Administración de aplicar de oficio las sentencias unificadas que hayan interpretado las normas en casos semejantes.

Es de aclarar en este punto que, la mera consagración del deber al que se ha hecho mención no garantiza en modo alguno que las autoridades administrativas lo acaten de manera irrestricta, razón por la que la Comisión también ideó la manera de hacerlo efectivo, consiguiendo con ello no sólo su obedecimiento sino la garantía del ciudadano de gozar de trato en condiciones de igualdad. Tal herramienta es el Mecanismo de Extensión de Jurisprudencia.

\subsection{PROCEDIMIENTO DE LA EXTENSIÓN DE JURISPRUDENCIA}

En los artículos 102 y 269 del CPACA se prevé un trámite ante la Administración y otro ante el Consejo de Estado, respectivamente.

A mi manera de ver, se parte de considerar el mecanismo de Extensión como un derecho de petición especial donde el ciudadano solicita a la Administración Pública que extienda una sentencia judicial unificada por advertir que se encuentra dentro de los mismos supuestos de hecho y de derecho, que pueden servir de base para la definición de

providencias unificadas del Consejo de estado sino también las de la Corte Constitucional. Sin embargo de este tema me ocuparé en el acápite 1.4.1.- ¿ذurisprudencia como fuente formal?

${ }^{4}$ Actual Consejero de Estado de la Sección Tercera. 
su situación jurídica, sin tener que agotar el tortuoso camino procesal que supone la instauración de la acción contenciosa en cualquiera de sus pretensiones.

Para estos efectos, se establece un trámite de acuerdo con el cual el interesado debe acudir inicialmente ante la Administración solicitando la aplicación del criterio jurisprudencial. Antes de la entrada en vigencia del Código General del Proceso (en adelante CGP) la Administración tenía treinta (30) días para resolver sobre la solicitud.

Sin embargo, con la reforma introducida por el mentado Código, el término se amplió considerablemente habida cuenta de que el artículo 614 del CGP ordenó la intervención de la Agencia Nacional de Defensa Jurídica del Estado. Siendo ello así, la Administración debe remitir el asunto a la citada Agencia quien cuenta con diez (10) días para resolver si emite concepto, y de ser así, tendrá veinte (20) días para hacerlo. Lo anterior quiere decir que la Administración cuenta con cuarenta (40) días para responder la petición de extensión siempre que la Agencia decida no rendir concepto, o con sesenta (60) días si la citada entidad resuelve hacerlo. Valdría la pena que el Congreso volviese a replantear la necesidad y utilidad de ésta reforma.

Una vez agotado dicho trámite, la Administración debe contestar la solicitud negando la petición o guardando silencio, casos estos en los cuales el interesado puede acudir al Consejo de Estado.

Cuando la Administración se niega a hacerlo o cuando guarda silencio, se activa la segunda parte del procedimiento en la que el ciudadano cuenta con la posibilidad de acudir al Consejo de Estado y poner en consideración tal actuación a afectos de que sea ésta Corporación la que ordene la Extensión y si a ello hay lugar, el reconocimiento del derecho. Para ello se debe adelantar una actuación en la que, previo traslado a la entidad correspondiente, se definirá la Extensión y adaptación de los efectos del fallo. En caso de que la jurisprudencia invocada no sea aplicable o no exista similitud de objeto y causa, se enviará el asunto al juez competente para que lo resuelva en la forma ordinaria. El trámite ante la Administración y el Consejo de Estado suspende el término para acudir a la jurisdicción.

Como vemos, este recurso se nutre de las sentencias de unificación expedidas por el Consejo de Estado y la Corte Constitucional para que sea la Administración la que las aplique o las extienda a través de actos administrativos cumpliendo a cabalidad con el deber que le es exigido en el artículo 10ㅇde la Ley 1437 de 2011.

\section{LA JURISPRUDENCIA COMO FUENTE FORMAL (ANÁLISIS CRÍTICO)}

Una vez entró en vigencia la Ley 1437 de 2011, las demandas de inconstitucionalidad no se hicieron esperar. Fue así como se impugnó la exequibilidad de los artículos 10, 102 y 
269 del CPACA invocando principalmente el desconocimiento del sistema de fuentes de nuestro ordenamiento jurídico.

La intervención del Consejo de Estado en los procesos acumulados números $D-8410$ y $D$-8427 tramitados en la Corte Constitucional da cuenta de ello:

Al sustentar el concepto de la trasgresión de los artículos $1^{\circ}, 6^{\circ}, 29$ y 230 de la Carta, la parte actora señala que el precepto parcialmente demandado infringe el postulado del Estado Social de Derecho y el principio de legalidad que le es inherente, al poner en manos del Consejo de Estado la facultad de imponer a todas las autoridades administrativas, legislativas y judiciales, en sus distintos órdenes, sectores y niveles, el deber de acatar los Precedentes jurisprudenciales establecidos en su línea jurisprudencial uniforme, abrogándose con ello "Ia función y capacidad de un poder constituyente primario y secundario", lo cual desconoce que nuestro ordenamiento jurídico superior establece que la jurisprudencia constituye apenas un criterio auxiliar de carácter no obligatorio. El alcance que el artículo $10^{\circ}$ atribuye a los Precedentes jurisprudenciales del Consejo de Estado, contradice los mandatos constitucionales en cita, al convertirlos en normas generales, impersonales y abstractas que por demás no han cumplido con el requisito de publicidad, contrariando el debido proceso. Se cuestiona asimismo el hecho de que el desconocimiento de los Precedentes jurisprudenciales pueda acarrear la anulación del acto y comprometer la responsabilidad de los servidores públicos.

En cuanto concierne a la violación de los artículos $4^{\circ}, 113,228$ y 230 de la Carta, los actores argumentan que la norma demandada desconoce el principio de separación e independencia de los poderes públicos, al obligar a todas las autoridades estatales a aplicar la jurisprudencia vinculante del Consejo de Estado. De igual modo, al establecer el "deber" de seguir los Precedentes jurisprudenciales de dicha Corporación, se está desconociendo que los jueces solamente están sometidos al imperio de la ley. (CE. Intervención en la demanda de constitucionalidad contra el artículo 10 de la Ley 1437 de 2011, Procesos acumulados D-8410 y 8427/2011, p. 5-20. Énfasis y cursivas en el original p 2-3).

Los sectores académico y doctrinal colombianos también hicieron parte de esa discusión. Juristas como Danilo Rojas Betancourt y José Luis Benavides Rueda fueron de la tendencia anotada al señalar que con la vigencia del Mecanismo de Extensión se estaba concibiendo a la jurisprudencia como fuente creadora de derechos y de situaciones jurídicas, pues a la Administración no le era suficiente atender a las normas constitucionales, legales y reglamentarias al momento de resolver las controversias que el administrado ponía a su consideración, sino que además se veía sometida a la interpretación que sobre las mismas hiciera su Juez controlador.

Por su parte, hubo quienes defendieron una postura opuesta, como el Ex Magistrado Rafael E. Ostau de Lafont Pianeta, quien partió de entender al Precedente, en sí mismo, 
como la regla que se extrae cuando se resuelve un caso anterior que sirve para decidir uno presente.

Para el citado jurista, la diferencia acerca de si el Precedente Judicial tiene la capacidad de crear reglas generales imperativas deviene de entender la fuente de la creación de ese Precedente, para lo cual es pertinente distinguir lo que sucede cuando se aplica un Precedente en el sistema europeo y lo que acontece con ello en el sistema anglosajón. Así, cuando se está en el segundo escenario los criterios para resolver el caso anterior se extraen de otro Precedente o directamente por creación del decisor.

Cuestión distinta a lo que acontece con la Extensión, como quiera que en este caso los criterios que sirven para resolver el caso actual siempre van a estar contenidos en una norma positivizada, no se parte nunca de la posición judicial sino de la norma jurídica y por lo tanto no puede colegirse que la jurisprudencia se convierta en fuente formal.

Participo de esta última percepción, pues de considerar a la jurisprudencia como fuente formal, las causales que permiten a la Administración separarse, incluso de la sentencia objeto de la solicitud de Extensión consagradas en el artículo 102 del CPACA., devendrían en inconstitucionales y a ello no ha habido lugar, por el contrario, la Corte ha declarado su exequibilidad.

Aunado a ello, es claro que el artículo 10 del CPACA no le otorga a este tipo de providencias el efecto de desconocer, derogar, subrogar o modificar normas constitucionales, legales o reglamentarias, pues la creación de normas jurídicas sigue radicada en el Poder Legislativo.

También es preciso anotar que más que desconocer el sistema de fuentes en el que se edificó el Estado colombiano, el Mecanismo de Extensión de Jurisprudencia se erige como una herramienta adicional de protección de los intereses del ciudadano y correlativamente como un instrumento que limita la discrecionalidad de las autoridades administrativas.

Dada la importancia de los argumentos expuestos en la intervención del Consejo de Estado en el proceso de constitucionalidad del artículo 10 del CPACA y lo aleccionadores en esta materia, se procederá a su transcripción in extenso:

Además de lo dicho hasta aquí, es importante destacar que el artículo $10^{\circ}$ de la Ley 1437 de 2011 no altera las fuentes de derecho consagradas en el artículo 230 de la Carta, ni convierte a la jurisprudencia del Consejo de Estado en una de ellas, pues conforme al artículo 102 de la misma ley, las autoridades administrativas pueden apartarse de su contenido y resolver negativamente las solicitudes formuladas por las personas, en el sentido de que se le hagan extensivas las jurisprudencias de unificación favorables proferidas por el Consejo de Estado, debiendo motivar las razones que se estimen pertinentes [...] 
Estas consideraciones llevan a colegir que lo que en la norma acusada se dispone no le otorga a la jurisprudencia unificada del Consejo de Estado el carácter de una fuente normativa (regla jurídica) con el efecto de desconocer, derogar o subrogar las normas constitucionales, legales o reglamentarias, sino, por el contrario, la de reafirmar la aplicación de tales disposiciones conforme a los pronunciamientos que sobre ellas y su alcance les ha dado el órgano de su conocimiento y decisión en los casos concretos, todo lo cual no hace otra cosa que propender al respeto y cumplimiento de las decisiones judiciales.

(...)

De manera categórica y concluyente se debe registrar, que el precepto demandado no se aparta de lo dispuesto en el artículo 230 constitucional y por lo mismo no le es contrario, pues al fin y al cabo, las fuentes formales de derecho que allí se mencionan siguen siendo las mismas. El precepto acusado, lo único que hace es garantizar que la Constitución, la ley y el reglamento, en cuanto fuentes formales de nuestro derecho, sean aplicadas de manera uniforme cuando quiera que sean idénticos los fundamentos fácticos y jurídicos de las situaciones a resolver. Dicho en otras palabras, el precepto acusado, en vez de infringir el mandato superior allí consagrado, tal como lo entienden de manera equivocada los demandantes, en realidad no está haciendo nada distinto a procurar su efectividad y correcta aplicación, sin perder de vista que el ordenamiento jurídico se inspira en el propósito de concretar los principios y valores constitucionales sobre los cuales se sustenta nuestra Estado Social de Derecho, lo cual riñe con la arbitrariedad y el despotismo de las autoridades. (CE. Intervención en la demanda de constitucionalidad contra el artículo 10으 de la Ley 1437 de 2011, Procesos acumulados D-8410 y 8427/2011, p. 5-20. Énfasis y cursivas en el original).

Después de demandada la constitucionalidad de los artículos 10, 102, 269 y 270 del CPACA, la Corte Constitucional decidió declarar exequibles las citadas disposiciones en Sentencias C-539, C-634, C-816 todas de 2011 y C-588 de 2012, al indicar que la jurisprudencia, no solo del Consejo de Estado sino también la de la Corte Suprema de Justicia y por supuesto la de ella misma, eran fuentes de derecho, es decir, fuentes formales capaces de crear por sí solas derechos y situaciones jurídicas concretas en los ciudadanos.

\section{1 VENTAJAS DEL SISTEMA COLOMBIANO}

La discusión del carácter vinculante que puede llegar a tener el Precedente Administrativo en países como España se enfrenta a valiosas discusiones que giran en torno a temas como que sobre las decisiones regladas no opera tal figura o que la validación judicial es una premisa necesaria para su aplicación. Ahora veremos cómo en nuestro ordenamiento esas talanqueras desaparecen por virtud del diseño institucional del Mecanismo de Extensión de Jurisprudencia.

Recordemos que quienes niegan el Precedente Administrativo como fuente de derecho en el ámbito reglado de las actuaciones de la Administración Pública explican que cuando 
existe una potestad reglada la Administración no está vinculada por sus Precedentes, sino directamente por la norma que ha creado su potestad, sería entonces una consecuencia directa de la legalidad. En estos casos la Administración sólo puede actuar en la medida que exista norma que la habilite y, como el Precedente no es norma, no puede constituirse en fuente que la habilita a seguirlo. (Ortíz, 1957, El Precedente Administrativo, p. 92-95).

Pues bien, en nuestro ordenamiento no hay lugar para tales disquisiciones jurídicas, dado que el nacimiento del Precedente se da con ocasión de la aplicación del Mecanismo de Extensión de Jurisprudencia, que a su vez viene nutrido de las providencias de unificación que el Consejo de Estado y la Corte Constitucional emitan sobre casos concretos, como consecuencia de la aplicación de una normativa específica.

Estas sentencias, se reitera, fueron incorporadas al sistema de fuentes formales de derecho por mandato del mencionado Tribunal Constitucional, de modo que así como la Constitución, la Ley y los Reglamentos, las sentencias de unificación vinculan a la Administración en sus actuaciones regladas.

En consecuencia, para efectos del reconocimiento de un derecho solicitado vía Extensión de Jurisprudencia es indiferente determinar si la facultad de la Administración es reglada o discrecional, lo que importa es que se cumplan los presupuestos de este Mecanismo para entender que se crean Precedentes Administrativos vinculantes en atención a las sentencias que le sirven de fundamento.

Lo propio acontece si tocamos otro de los inconvenientes que tanto la doctrina como la jurisprudencia española han advertido para no concebir el Precedente Administrativo con valor jurídico en ese ordenamiento, cual es el de la necesidad de validación judicial previa.

En el caso colombiano ese aspecto no constituye una barrera sino un presupuesto de existencia del Precedente Administrativo, ya que la Administración crea sus propios modelos a partir de las decisiones judiciales unificadas que los órganos de cierre de la Jurisdicción Contenciosa y de la Constitucional han proferido en las materias de su competencia.

Esta es sin duda una forma de llegar al reconocimiento de Precedentes Administrativos sin que medie el problema que enfrenta Europa en donde los jueces niegan su carácter vinculante arguyendo que debe existir una sentencia judicial que declare la legalidad del acto administrativo invocado como Precedente. Nuestro sistema, y en particular, el Mecanismo previsto en el artículo 102 y 269 del CPACA, determina una valoración de sentencias judiciales previas como requisito NO del acto que sirve de parangón para alegar la vulneración del derecho a la igualdad, sino de decisiones judiciales que estudien casos similares que puedan ser aplicados a uno actual. Es otras palabras, el Precedente Administrativo se edifica a partir de esas providencias, lo que obliga a que la Rama Judicial se empodere de un atributo ausente por estos días, de coherencia en sus decisiones. 
Ahora, es importante anotar que la parte de las sentencias que debe servir de referencia para solicitar la Extensión es la ratio decidendi, toda vez que constituye el criterio decisivo de la providencia judicial, y por lo tanto, es la que debe vincular al funcionario administrativo en su decisión. En otras palabras, la regla jurídica que debe extender la Administración al particular es la que resuelva el problema jurídico planteado en su momento ante el Juez Administrativo.

\section{CONCLUSIONES}

De acogerse de manera seria y responsable este Mecanismo, los resultados en términos de descongestión administrativa serían importantes, toda vez que la Administración iría construyendo líneas de decisión en circunstancias muy concretas para resolver en esa sede las inquietudes de los ciudadanos.

La aplicación eficiente del Mecanismo de Extensión de Jurisprudencia, en la forma anotada, genera espacios de interlocución, de acercamiento democrático y de evolución social entre Administración y administrado con el ejercicio simple de un derecho de petición que a la vez ofrece un escenario para la solución alternativa de conflictos, de manera que sus inquietudes y derechos sean definidos en sede administrativa con apoyo en pronunciamientos judiciales sólidos, es decir, previos, uniformes y reiterados en casos concretos.

Existe entonces un argumento de autoridad para la Administración consistente en la interpretación de normas jurídicas por parte del órgano de cierre de lo Contencioso Administrativo y de la Jurisdicción Constitucional, que al mismo tiempo fungen como controladores de las actuaciones administrativas, lo que otorga más fuerza, importancia y ejecutividad al Mecanismo.

Es por ello que, además de ganar institucionalidad, el Mecanismo de Extensión permite que en el sistema jurídico se exija cada vez más coherencia, no sólo al interior de la jurisdicción sino de la Administración Pública, en orden a que se respeten las providencias de unificación para garantizar que los principios de confianza legítima y de seguridad jurídica sean más que una quimera. Sin duda, la efectivización del Precedente judicial contribuirá a la consolidación del Precedente Administrativo con carácter vinculante.

Una consecuencia casi inadvertida es la relacionada con el flujo de caja de las entidades públicas, pues sin duda la descongestión redunda en un menor costo económico para el Estado como quiera que los recursos que se invierten en su defensa -las más de las veces de manera inocua- no serían de la magnitud que se presenta actualmente, lo que genera un resultado positivo y una mayor eficiencia en términos de gestión pública. A ello se suma el elevado gasto que debe asumir el Estado por conceptos de intereses y actualizaciones monetarias al cabo de un proceso largo y engorroso, el sacrificio que 
debe hacerse en materia de obras de infraestructura e inversiones sociales por el hecho de estar asumiendo esos costos innecesarios, entre otros.

A su turno, el particular vería satisfechos sus intereses sin el sometimiento a un proceso judicial y sin menoscabo de sus intereses patrimoniales. De funcionar la propuesta, el ciudadano vería en la Administración un verdadero garante de sus derechos y no un enemigo a ultranza como actualmente lo vislumbra.

Otro beneficio de la aplicación del Mecanismo está representado en la descongestión de los despachos judiciales, en la medida en que el Juez se ocuparía de aquellos casos sui generis o que requieren un discernimiento especial, o un mayor grado de exigencia argumentativa. La institucionalidad entonces desde el punto de vista judicial y administrativo recuperaría valor social.

Llevar a cabo el Mecanismo de Extensión de Jurisprudencia con miras no sólo a la creación de Precedentes Administrativos con valor jurídico en nuestro sistema representa más ganancias que pérdidas para la sociedad y para el valor de lo público, ya que pese a las numerosas críticas que no se han hecho esperar, creo sin temor a equívocos, que el desenlace de la figura cooperaría en la generación de la ausente credibilidad en las instituciones, siempre que la Administración y el aparato judicial se capaciten y creen dentro de sí una nueva forma de resolver las situaciones planteados por los ciudadanos al margen de los procesos judiciales.

Soy de la posición de que la vinculatoriedad del Precedente Administrativo se da no sólo porque la decisión dependa de una sentencia unificada sino porque se trata de aplicar directamente principios generales del derecho que resultan imprescindibles a la hora de controlar a la Administración y de hacer que ella misma se auto controle en procura de alcanzar la anhelada igualdad material. Esos principios no son otros que los de Buena Fe, Seguridad Jurídica, Confianza Legítima e Interdicción de la Arbitrariedad. No obstante, mientras ello ocurre, la aplicación del Mecanismo de Extensión de Jurisprudencia contribuiría eficazmente al logro de ese cometido.

Vistas así las cosas, se impone pensar no solamente en el logro de igualdad en la creación de las normas sino en su aplicación, en la medida en que es en sede del órgano ejecutor del Estado que se definen derechos, obligaciones o se imponen deberes o sanciones. (Tirado, 2010, p.140-141). Esto no es más que una de las manifestaciones de la llamada igualdad material.

Aceptar el funcionamiento de la propuesta de este trabajo de grado ayudaría en la creación de una técnica de coherencia del sistema y de control de la discrecionalidad administrativa, que garantiza la observancia de los principios atrás enunciados. 
Esta figura ofrece, se reitera, más beneficios que desventajas para los extremos de la relación jurídica, es decir, el gobierno y los particulares.

\section{REFERENCIAS BIBLIOGRÁFICAS}

Arana, J., Benavides, V., Sheffer, J., Y Sendín, M. (2007). Derecho Administrativo Iberoamericano. Discrecionalidad, Justicia Administrativa y entes Reguladores). Costa Rica: Congreso Iberoamericano de Derecho Administrativo.

Bogotá, Colombia. Consejo de Estado. Documento obtenido el 21 de marzo de 2014 en respuesta al derecho de petición solicitado por Yudy Carolina Leal Galán el día 12 de marzo de ese mismo año: Conclusiones Sesión No. 77 del 24 de agosto de 2009. Comisión redactora del Nuevo Código Contencioso Administrativo. Transcripción Sesión No. 77 del 24 de agosto de 2009. Comisión Redactora del Nuevo Código Contencioso Administrativo. Transcripción Sesión Sala Plena. 23 de noviembre de 2009. Sala Plena del Consejo de Estado.

Asamblea Legislativa de la República de Costa Rica. (24 de abril de 2006). Ley 8508 de 2006. Código Procesal Contencioso-Administrativo. Recuperado de http://www. pgr.go.cr/scij/scripts/TextoCompleto.dll?Texto\&nNorma=57436\&nVersion= 63015\&nTamanoLetra=10\&strWebNormativa=http://www.pgr.go.cr/ scij/\&strODBC=DSN=SCIJ_NRM;UID=sa;PWD=scij;DATABASE =SCIJ_ NRM; \&strServidor=\\pgrO4\&strUnidad=D:\&strJavaScript=NO

Congreso de la República de Colombia. (21 de septiembre de 2010). "PONENCIA PARA PRIMER DEBATE AL PROYECTO DE LEY 315 DE 2010 CÁMARA, 198 DE 2009 SENADO, por la cual se expide el Código de Procedimiento Administrativo y de lo Contencioso Administrativo". Recuperado de: http://servoaspr.imprenta.gov.co:7778/gacetap/ gaceta.mostrar_documento?p_tipo=11\&p_numero=315\&p_consec $=26890$

Congreso de la República de Colombia. (18 de enero de 2011). Ley 1437 de 2011. Por la cual se expide el Código de Procedimiento Administrativo y de lo Contencioso Administrativo. Recuperado de http://www.secretariasenado.gov.co/senado/ basedoc/ley/2011/ley_1437_2011.html.

Congreso de la República de Colombia. (18 de enero de 2011). Ley 1437 de 2011. Exposición de motivos. Recuperado de http://servoaspr.imprenta.gov.co/diariop/diario2. pdf?p_tipo=01\&p_numero $=1437 \& p \_f e c h a=18 / 01 / 2011 \& p \_c o n s e c=1300559$.

Congreso de la República de Perú. (10 de abril de 2001). Ley 27444 de 2001. Ley del Procedimiento Administrativo General. Recuperado de: http://www.mincetur.gob. pe/newweb/portals/0/LEY_27444_DERECHOS_DEL_ADMINISTRADO.pdf. 
Consejo de Estado. (24 de noviembre de 1995). Sentencia 3298. M.P. Rafael Ariza Muñoz. Recuperada de http://www.consejodeestado.gov.co/nuevacondere.asp.

Consejo de Estado. (28 de enero de 2010). Sentencia 11001-03-24-000-2004-00273-01. M.P. Rafael E. Ostau de Lafont Pianeta. Recuperada de http://www.consejodeestado. gov.co/nuevacondere.asp.

Consejo de Estado. (18 de julio de 2012). Sentencia 11001-03-24-000-2006-00170-00. M.P. María Claudia Rojas Lasso. Recuperada de http://www.consejodeestado.gov. co/nuevacondere.asp.

Consejo Parlamentario. (23 de mayo de 1949). Ley Fundamental de la República Federal de Alemania. Recuperado de: http://es.wikipedia.org/wiki/Ley_Fundamental_ para_la_Rep\%C3\%BAblica_Federal_de_Alemania.

Cortes Generales. (26 de noviembre de 1992). Ley 30 de 1992. Régimen Jurídico de las Administraciones Públicas y del Procedimiento Administrativo Común. Recuperado de: http://www.fomento.gob.es/MFOM/LANG_CASTELLANO/DIRECCIONES GENERALES/AVIACION_CIVIL/INFORMACION/NORMATIVA/NORMATIVA_BASICA/ DISPOSICIONES_BASICAS/DISPOSICONES_INSPECCION/Ley_30_1992.htm.

Díez, S. (2008). El Precedente administrativo. Fundamentos y eficacia vinculante. Madrid: Marcial Pons.

Documento Guía de Preparación para la intervención del Consejo de Estado en el proceso de exequibilidad contra el artículo 10 de la Ley 1437 de 2011 identificado con los números D-8410 y D-8427 que se tramitó en la Corte Constitucional. No publicable.

Miele. A, (1963). Principi di Diritto ammnistrativo, Tomo I, Padova.

García de Enterría, Eduardo y Fernández Rodríguez, Tomás Ramón, 2011, Curso de Derecho Administrativo. Civitas Ediciones. Edición 15. Volumen I.

Novoa, E. (2007). El derecho como obstáculo al cambio social. Madrid: Siglo veintiuno editores.

Ollero, A. (2005). Igualdad en la aplicación de la ley y Precedente judicial. Madri: CEC.

Ortíz Díaz, J. (1957). El Precedente Administrativo. Revista Andaluza de Administración Pública, ISSN 0034, No. 24, 75-116.

Ostau de Lafont Pianeta, R. (2014). Solución de controversias Contractuales. Bogotá: Universidad Externado de Colombia. 
Pressuto, W. (1930). Instituzzioni di Ditrito amnistrativo iataliano, Roma: 2 Ed.

Quintero, G. (2012). Buenas Prácticas, Ética y Derecho Disciplinario. Reflexiones Académicas en Derecho Disciplinario y Contratación Estatal. Segundo Congreso Internacional de Derecho Disciplinario, Volumen III, 2-55.

Ranelleti, O. (1913). La consuetedine come fonte del diritto pubblico interno. Roma: Rivista di Dirito pubblico.

Tirado, J. (2010). Modernizando el Estado para un país mejor: Ponencias del IV Congreso de Derecho Administrativo. Lima, Perú: Palestra Editores.

Valbuena, G. (2008). La defraudación de la confianza legítima. Aproximación crítica desde la teoría de la responsabilidad del Estado. Bogotá D.C: Universidad Externado de Colombia.

Vanegas, E. (2012). El Mecanismo de Extensión de Jurisprudencia a Terceros en el nuevo Código de Procedimiento Administrativo y de lo Contencioso Administrativo. Bogotá, Colombia: Universidad de los Andes. Sin publicar. 